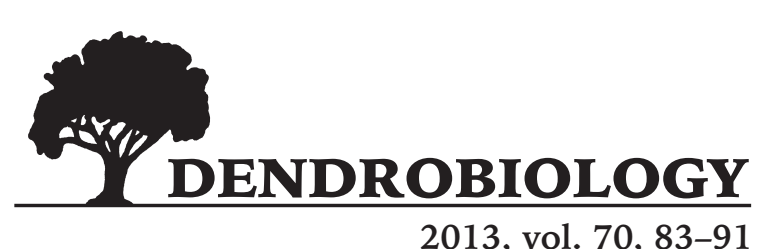

http://dx.doi.org/10.12657/denbio.070.009

\author{
Jiři Hřib, Václav Adamec, Vojtěch Sedláček, Božena Vooková
}

\title{
Passive defense in somatic embryos of Abies alba from two cell lines tested with Phaeolus schweinitzii
}

\author{
Received: 08 January 2013; Accepted 13 March 2013
}

\begin{abstract}
Differential inhibition in growth of fungus Phaeolus schweinitzii inoculum was tested with somatic embryos of two cell lines of silver fir (Abies alba Mill.) by the method of dual cultures with pre-cultivation of somatic embryos and subsequent removal. It was confirmed that inhibitory substances from pre-cultivated somatic embryos L27 spreading to agar cultivation medium by simple diffusion cause greater inhibition of tester mycelial growth during subsequent co-cultivation compared to somatic embryos L122. Characteristics of embryogenic cell lines L27 and L122, from which somatic embryos were formed, are provided. Increased levels of peroxidase activity characterized the cell line L27. Natural non-induced constitutive defense of plant somatic embryos established by quantitatively measured restriction of growth in tester Phaeolus schweinitzii was discussed.
\end{abstract}

Additional key words: silver fir, somatic embryos, mycelial growth, dual cultures, passive defense, fungal tester

Address: J. Hřib, Institute of Plant Genetics and Biotechnology, Slovak Academy of Sciences, Akademická 2, P.O. BOX 39A, 95007 Nitra, Slovak Republic, e-mail: jhrib1@nbox.cz; V. Adamec, Department of Statistics and Operational Research, School of Business and Economics, Mendel University, Zemědělská 1, 61300 Brno, Czech Republic, e-mail: vadamec@mendelu.cz; V. Sedláček, Department of Biochemistry, Faculty of Science, Masaryk University, Kamenice 5, 62500 Brno, Czech Republic, e-mail: 21931@mail.muni.cz; B. Vooková, Institute of Plant Genetics and Biotechnology, Slovak Academy of Sciences, Akademická 2, P.O. BOX 39A, 95007 Nitra, Slovak Republic, e-mail: nrgrvook@savba.sk

\section{Introduction}

Defense is a common strategy in plants which, being immobile, have difficulty in avoiding their enemies. Plants contain an extremely rich and diverse array of chemicals. Many of these chemicals were originally thought to be secondary by-products of cellular mechanism, hence their common name secondary plant metabolites (Berryman 1988). There are two basic approaches to defense: passive or constitutive defense, which is analogous to fortification, and dynamic or induced defense, which is more similar to counter attack (Cowling and Horsfall 1980).
The report of using embryogenic tissue lines in studying host-parasite interaction between Scots pine and Gremmeniella abietina was presented by Terho et al. (2000). The role of Pinus nigra lectin (PNL) during initial stages of the host-parasite interaction was described by Nahálková et al. (2001).

In our laboratory, defense reactions of conifers, such as Pinus nigra megagametophyte in dual cultures with the basidiomycete Phaeolus schweinitzii were studied. Strong defense reaction of the megagametophyte against the fungus was observed in pre-cultivated cultures. After megagametophyte removal, the inhibition of mycelial growth by diffused 
substances (DS) was stronger than in the case of simultaneous inoculation of megagametophytes and the fungus. These results indicate that substances diffused into the agar medium are responsible for defense reactions in vitro (Hřib et al. 1996). Differential mycelium growth of the fungus Phaeolus schweinitzii was observed in the presence of Pinus nigra embryogenic and non-embryogenic calli. We have evidence that defense system in European black pine is probably formed at the very early stage of somatic embryo development (Hřib et al. 1995). Defence reactions of embryonal suspensor mass, precotyledonary, cotyledonary and desicated cotyledonary somatic embryos of Algerian fir (Abies numidica) were tested by dual cultures with fungus Phaeolus schweinitzii (Vooková et al. 2006).

SDS analysis showed differences in the accumulation of low molecular weight storage proteins in hybrid fir somatic embryos (Salaj et al. 2004). Storage proteins can play an important role in the defense of embryos (Vooková et al. 2006).

Objective of this study is to verify presence and quantify magnitude of a non-induced passive defense in somatic embryos of two silver fir cell lines producing substances which diffuse in medium during pre-cultivation with tester fungus Phaeolus schweinitzii in dual cultures. Detection of non-induced passive defense of Abies alba against fungal tester Phaeolus schweinitzii can provide helpful information unavailable in previous reports.

For better understanding the differences in defense reactions of somatic embryos L27 and L122, guaiacol peroxidase activity analysis and total protein concentration were determined.

\section{Material and methods}

\section{Plant material}

The embryogenic cell lines L27 and L122 were initiated from different immature zygotic embryos of silver fir (Abies alba Mill.). Immature cones were collected on July 26th from open-pollinated family D5 tree in Dobroč primeval. Induction of embryogenic tissue on SH medium (Schenk and Hildebrandt 1972) supplemented with $5 \mu \mathrm{M}$ 6-benzylaminopurine (BAP), and maturation of somatic embryos on modified MS medium (Murashige and Skoog 1962) supplemented with $40 \mathrm{~g} / 1$ maltose, $100 \mathrm{~g} / 1$ polyethylene glycol-4000 and $40 \mu \mathrm{M}$ abscisic acid $(( \pm)$ cis-trans, ABA) was published by Vooková and Kormu ák (2002). Mature somatic embryos were isolated from embryogenic tissue and placed in Petri dish ( $\varnothing 60$ $\mathrm{mm}$ ) and subjected to high relative humidity treatment. Petri dish was opened and placed on moist filter paper in Petri dish $(\varnothing 90 \mathrm{~mm})$, which was sealed with parafilm. The embryos in Petri dish were culti- vated in the dark at $22-23^{\circ} \mathrm{C}$ during three weeks. In this way, desiccated cotyledonary somatic embryos obtained from cell lines L27 and L122 were used in the experiment.

\section{Fungal tester}

The fungus Phaeolus schweinitzii (Fr.) Pat., isolate No. 151 was used as a model tester. This strain was obtained from the Collection of Wood Destroying Fungi, J. E. Purkyně University (now Masaryk University). This culture was grown at $23 \pm 1^{\circ} \mathrm{C}$ in the dark on 3\% malt extract and 2\% Difco Bacto Agar.

\section{Dual culture}

Tests were carried out on agar MS medium without growth regulators, supplemented with $20 \mathrm{~g} / \mathrm{l}$ sucrose and $10 \mathrm{~g} / \mathrm{l}$ Difco Bacto Agar in Petri dishes ( $\varnothing 90$ $\mathrm{mm})$. The somatic embryos L27 and L122 were placed at the margin of the dishes and were cultured 14 days in the dark on the MS medium and then removed. In day 14 , fungal inoculums $10 \times 10 \mathrm{~mm}$ were taken from the base culture on malt agar and were inserted in the Petri dishes about $2.5 \mathrm{~cm}$ from the embryo imprint. Position of the somatic embryos was marked on the bottom of Petri dish by Centropen ${ }^{\circledR}$. In the first variant, only one somatic embryo was placed. In the second variant, three somatic embryos were used. The controls contained only the fungus inoculums. The cultures were maintained at $23 \pm 1^{\circ} \mathrm{C}$ in the dark. Experimental treatments included two factors: line of somatic embryos and number of embryos. Factor of embryo line had two levels: L27 or L122. Factor number of embryos had two levels: single embryo (E1) or three embryos (E3). Control dishes were not treated with embryos to display uninhibited growth of fungal mycelium. Dishes treated with embryo imprint were anticipated to show growth of mycelium affected by differential constraints due to line of treatment somatic embryos and number of treatment embryos. The measurements of fungal mycelium size were taken in 2-day intervals in the direction towards the embryos and in the opposite direction, starting with day zero and ending with day 10-post inoculation. Mycelium size in control dishes was measured on four peripheral spots corresponding to two perpendicular diameter axes. The measurements were taken using a $\mathrm{mm}$ rule in counter light from the bottom of the dish. For every combination of experimental treatments and control, four replications of Petri dish were established.

\section{Peroxidase analysis of embryogenic tissue}

Peroxidase activity was determined spectrophotometrically (Ultra Spec UV 2100, GE Healthcare) using guaiacol as substrate at $436 \mathrm{~nm}$ with molecular absorption coefficient $25000 \mathrm{l} / \mathrm{mol} / \mathrm{cm}$ (Bergmeyer 
1974). The reaction mixture containing $0.1 \mathrm{M}$ potassium phosphate buffer ( $\mathrm{pH} 7.0$ ), $0.3 \mathrm{mM}$ guaiacol and $0.15 \mathrm{mM}$ hydrogen peroxide was temperated at $25^{\circ} \mathrm{C}$. The enzyme reaction was started by adding $0.1 \mathrm{ml}$ of the supernatant from embryogenic cell line L27 or line L122.

\section{Protein determination of embryogenic tissue}

For protein extraction, $0.5 \mathrm{~g}$ of embryogenic tissue of silver fir (Abies alba) cell lines (L27, L122) was used. After homogenization in Potter-Elvehjem homogenizator, the mixture was centrifuged at 22,000 g for $5 \mathrm{~min}$. The resulting supernatant was used for the analysis. In the protein assay bicinchoninic acid was used (Smith et al. 1985). Proteins were quantified with bovine serum albumin using standard by QuantiPro BCA Assay Kit (Sigma, USA). The protein concentration was measured in three replicates and represented by mean \pm standard deviation.

\section{Statistical analysis}

Early review of mycelium growth data from control and experimental cultivations pointed to a sigmoid growth process, represented by three-parametric logistic equation assumed by Koch (1975) for modeling mycelial growth

$$
Y=\frac{\alpha}{1+e^{\left(\left(\beta_{0}-X\right) / \beta_{1}\right)}}+\varepsilon
$$

In this equation, $\mathrm{Y}$ denotes the size of mycelium [mm], $\alpha$ is the coefficient of upper asymptote of the logistic curve, $\beta_{0}$ is the coefficient representing time required to reach inflection point placed approximately at $\alpha / 2, \beta_{1}$ was the scale parameter indicating time required for mycelium to grow from half to $1 /\left(1+e^{-1}\right) \approx 3 / 4$ of the asymptotic height, $\mathrm{X}$ was number of cultivation days from inoculation to the mycelium size measurement and $\varepsilon$ represented random disturbances. Interpretation of the logistic curve parameters is illustrated in Fig. 1 (Pinheiro and Bates 2000).

Estimated parameters of the logistic model were anticipated to be positive. Model coefficients, especially $\alpha$ and to a smaller extent $\beta_{0}$ and $\beta_{1}$ are assumed to reflect apparent inhibitory effects of diffused substances (DS) from pre-cultured somatic embryos on treated mycelium growth. Several generalized fixed and mixed models were, as a result, constructed to quantify extent of the growth inhibition in response to experimental treatment or control. A general logistic model was constructed early for the combined data. In models with experimental treatments, the parameters were allowed to fluctuate. Competing nested models were compared by generalized likelihood ratio $\chi^{2}$ test to determine simultaneous signifi-

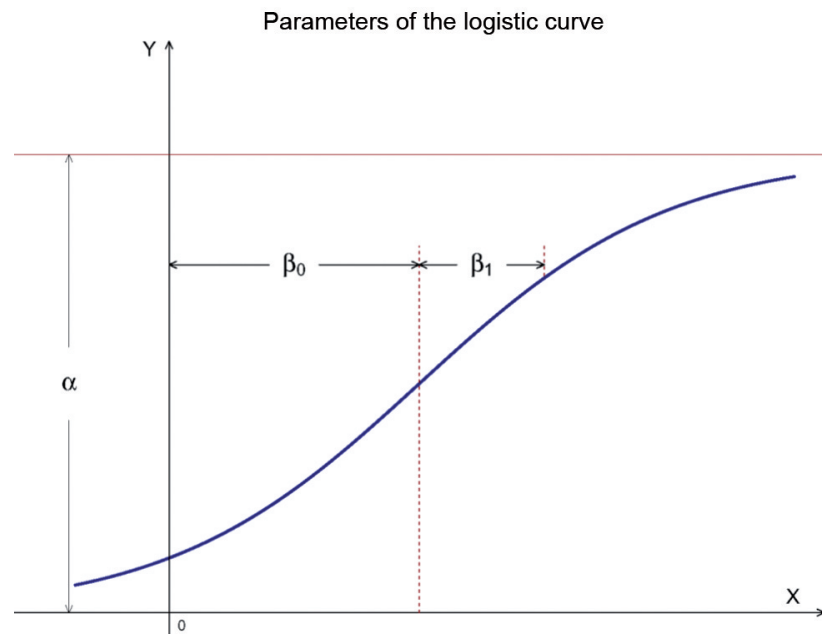

Fig. 1. Interpretation of the logistic curve parameters

cance of the added effects. Adding random effects of Petri dishes on the logistic parameters was aimed at validating random variation associated with the dishes apart from the error term. Solutions to the coefficients $\alpha, \beta_{0}$ and $\beta_{1}$ were obtained by iterative algorithm.

Estimated parameterizations applied by statistical software due to identifiability, were linearly transformed to facilitate interpretations and allow comparisons of treatment effects. Linear combinations of the coefficients were estimated by $\beta^{*}=C^{\prime} \beta$, where $C$ is a matrix storing coefficients of linear parametric combinations and $\beta$ is vector of the untransformed coefficients derived by software. Covariance matrix of the linear combinations was obtained by applying $\operatorname{Var}\left(\beta^{*}\right)=C^{\prime} \operatorname{Var}(\beta) C$, where $\operatorname{Var}(\beta)$ is the covariance matrix of the primary coefficients. Statistical significance of the estimates and parametric combinations was verified by t-test.

Properties of the transformed growth curves were evaluated by finding root of the equation received by taking second derivative of the model with respect to cultivation time and setting equal to zero. Maximum gradient at the point of inflection was computed by maximizing the model first derivative with respect to cultivation time. Statistical analyses and production of plots were accomplished with $\mathrm{R}$ software (www.r-project.org), principally the built-in nlme library (version 3.1-104) and lattice library (version 0.20-6).

\section{Results}

Embryogenic cell lines L27 and L122 differed during proliferation process. Embryogenic tissue of line L27 showed faster browning during sub-cultivation relative to embryogenic tissue line L122 (Fig. 2). These cell lines differed also in number of mature somatic embryos obtained by maturation process in 2008 . 

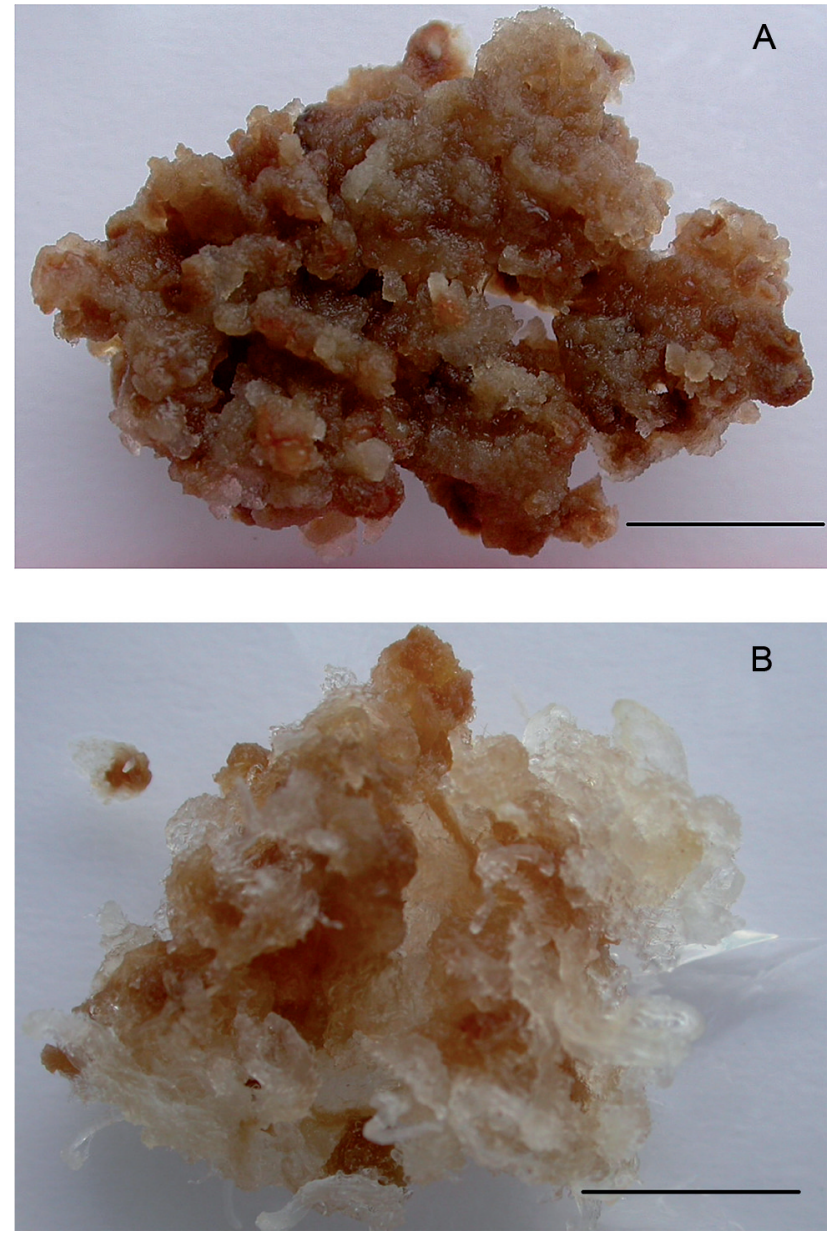

Fig. 2. Embryogenic tissues line L27(A) and line L122(B) of silver fir (Abies alba) after culturing for 27 days. Scale is 5 $\mathrm{mm}$

Totally $74.87 \pm 13.98$ somatic cotyledonary embryos were obtained from $1 \mathrm{~g}$ of L27 embryogenic tissue. This number included $37.76 \pm 7.20$ quality somatic embryos with fully developed radicula and at least 4 cotyledons. Cell line L122 was more productive; totally $95.86 \pm 4.46$ somatic embryos and 62.59 \pm 8.75 quality embryos were obtained from $g$ of

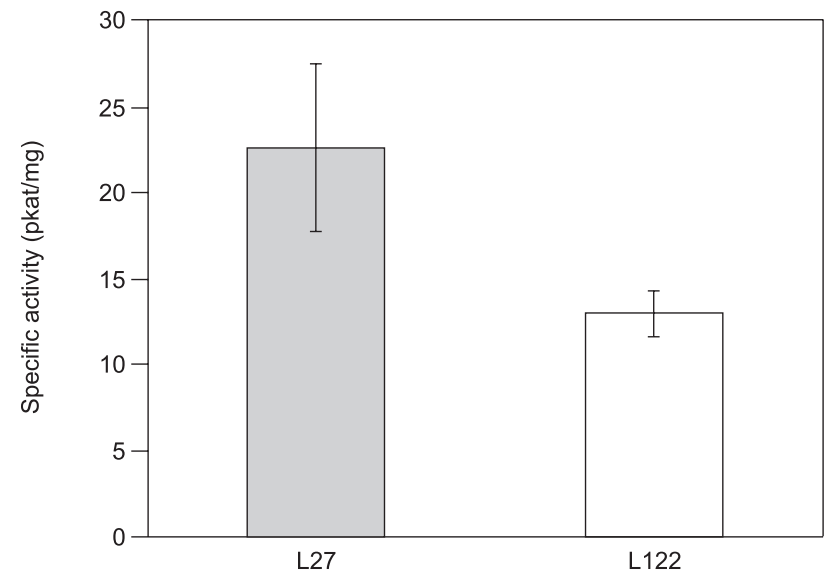

Fig. 3. Peroxidase activity of silver fir (Abies alba) embryogenic tissues represented by mean \pm standard deviation from three replicates

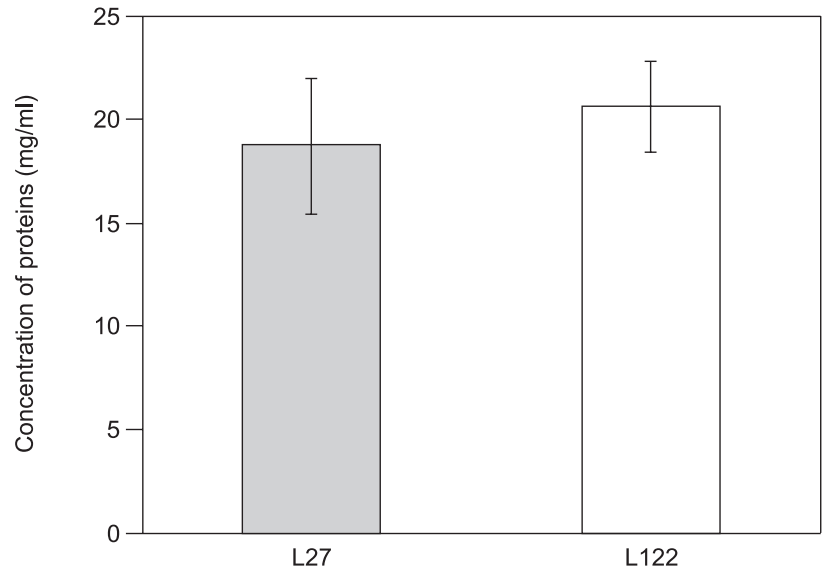

Fig 4. Concentration of proteins in embryogenic tissues of silver fir (Abies alba) represented by mean \pm standard deviation from three replicates

embryogenic tissue. Subsequently, specific peroxidase activity in embryogenic tissue of Abies alba was measured. The specific peroxidase activity $22.70 \pm$ $4.90 \mathrm{pkat} / \mathrm{mg}$ of protein was found higher in cell line L27 relative to line L122 with $13.00 \pm 1.30$ pkat/mg of protein (Fig. 3).

Somatic embryogenic tissue extracts from cell lines L27 and L122 were prepared in protein amounts $18.64 \pm 3.24 \mathrm{mg} / \mathrm{ml}$ and $20.59 \pm 2.20 \mathrm{mg} / \mathrm{ml}$, respectively (Fig. 4).

The coefficients of logistic model obtained from the combined data, which disregard the experimental variants, line of somatic embryos and amount of DS corresponding to the number of embryos, were significantly different from zero $(P<0.01$, Table 1$)$. Residual standard deviation from the combined model was $\sigma_{\mathrm{E}}=2.20$. In the final nonlinear mixed-effects model with experimental treatment grouping, the estimated error standard deviation was smaller $\left(\sigma_{\mathrm{E}}=0.81\right)$ compared to the combined model. The mixed model, in overall, had better fit.

In accordance with previous anticipation, the experimental treatments caused inhibition to speed of growth in Petri dishes treated with DS from different number of somatic embryos of $A$. alba in comparison to the untreated control variants. Linearly reparametrized coefficients for the experimental treatment combinations of embryo cell lines, DS from different

Table 1. Estimated logistic coefficients, residual standard deviation and associated $95 \%$ confidence limits for the general fixed-effects model

\begin{tabular}{cccc}
\hline Parameter & Estimate & $2.5 \%$ & $97.5 \%$ \\
\hline$\alpha$ & 18.78 & 16.26 & 21.29 \\
$\beta_{0}$ & 6.36 & 5.66 & 7.07 \\
$\beta_{1}$ & 1.84 & 1.42 & 2.26 \\
$\sigma_{\mathrm{E}}$ & 2.20 & 1.95 & 2.52 \\
\hline
\end{tabular}

$\mathrm{f}(\mathrm{x})$ at point of inflection $=9.39 \mathrm{~mm}$; maximum gradient $=2.55$ $\mathrm{mm}$ /day 
Table 2. Estimated parameters of logistic curve, response at inflection point and maximum gradient at inflection point for experimental treatment fixed-effects combinations from the treatment effects model

\begin{tabular}{lccccc}
\hline $\begin{array}{c}\text { Combi- } \\
\text { nation }\end{array}$ & $\alpha$ & $\beta_{0}$ & $\beta_{1}$ & $\begin{array}{c}\mathrm{f}(\mathrm{x}) \text { at } \\
\text { point of } \\
\text { inflection } \\
\text { [mm] }\end{array}$ & $\begin{array}{c}\text { Maximum } \\
\text { gradient of } \\
\text { growth at point } \\
\text { of inflection } \\
\text { [mm/day] }\end{array}$ \\
\hline L27:E1 & $15.71^{* *}$ & $6.35^{* *}$ & $1.83^{* *}$ & 7.86 & 2.15 \\
L27:E3 & $15.21^{* *}$ & $6.35^{* *}$ & $1.83^{* *}$ & 7.61 & 2.08 \\
L122:E1 & $19.64^{* *}$ & $6.35^{* *}$ & $1.83^{* *}$ & 9.82 & 2.69 \\
L122:E3 & $17.29^{* *}$ & $6.35^{* *}$ & $1.83^{* *}$ & 8.65 & 2.37 \\
\hline Control & $25.70^{* *}$ & $6.35^{* *}$ & $1.83^{* *}$ & 12.85 & 3.52 \\
\hline
\end{tabular}

Notation: ${ }^{* *}$ estimated coefficients significant at $\alpha=0.01$

number of somatic embryos or untreated control and respective standard errors were deduced from the estimated model. Linearly reparametrized coefficients were statistically different from zero $(P<0.01$, Table $2)$. Among logistic model coefficients, only $\alpha$ coeffi- cients, representing the upper asymptotic height, showed oscillations among experimental variants. Relative to the control dishes, the presence of DS from embryos significantly reduced the height of the logistic asymptote. Parameters $\beta_{0}$ and $\beta_{1}$, on the contrary, appeared unaffected by the presence or absence of DS from plant somatic embryos during mycelium cultivation. The extent of mycelium growth suppression caused by experimental variants is depicted in Figure 4. Relative to experimental variants, control Petri dishes displayed unimpaired growth with inflection point at larger mycelium size and larger growth gradient at the inflection point.

There is indication, that presence of the DS from somatic embryos relative to control, embryo line of Abies alba (L27 or L122) and DS from one or three embryos slowed down the speed of mycelium growth. Impact of the experimental variants of embryo line, DS from number of somatic embryos on logistic coefficients of the upper asymptote $\alpha$ is presented in Table 3. Magnitude of the general inhibitory effects by DS

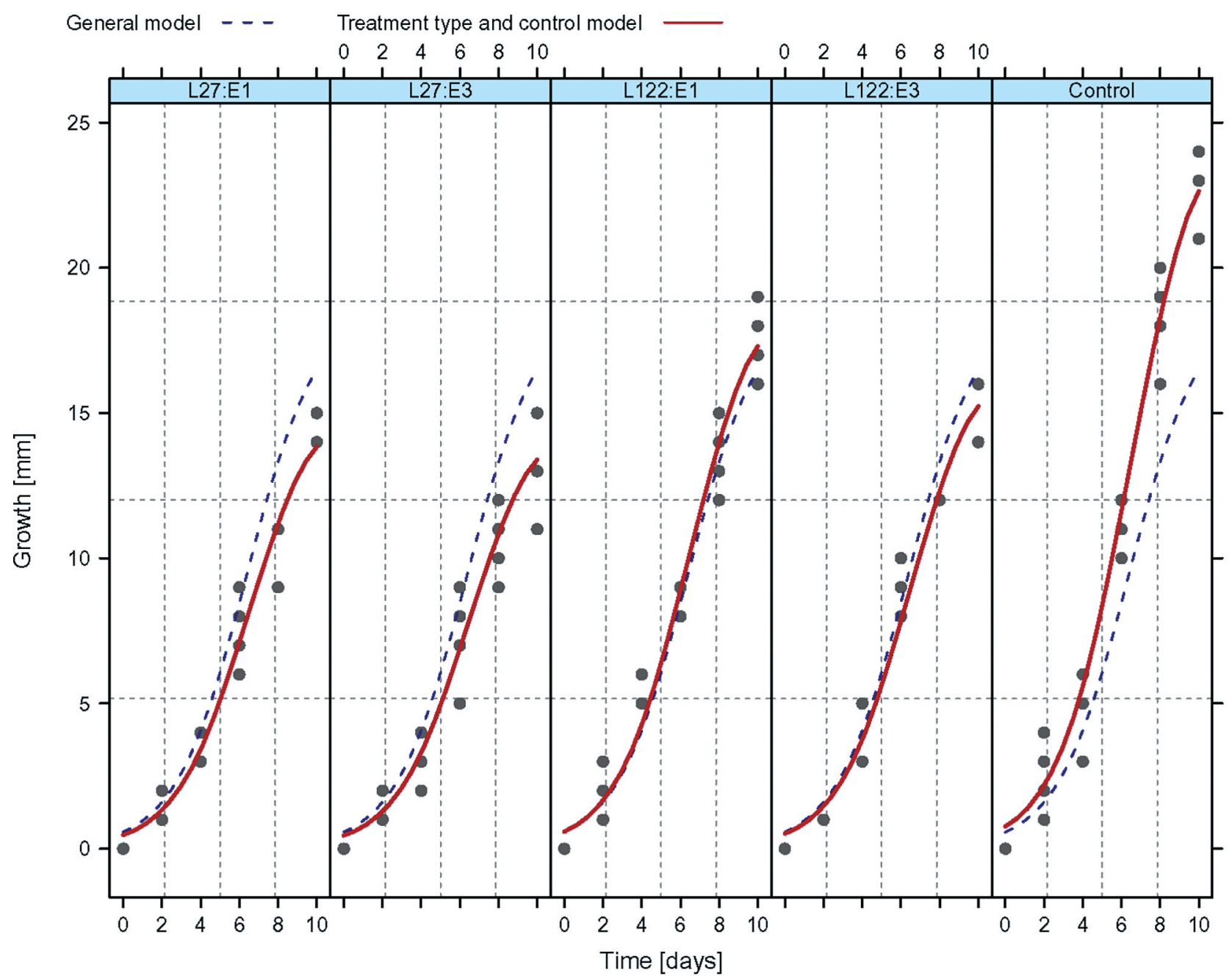

Fig. 5. Estimated logistic curves for combinations of embryo line of A. alba (L27 or L122) or control and number of somatic embryos (single or three inserted embryos) in the treatment or control model and the unstructured general model. Points designate actual measurements 
from added somatic embryos on mycelial growth is shown in the form of tests of mean effects. It can be concluded that somatic embryos L27 provide stronger inhibitory effect on mycelium growth compared to somatic embryos L122. Also, presence of DS from three embryos in general causes a larger inhibition of mycelium growth, relative to presence of DS from just one embryo. Statistically significant averaged effects of the DS from embryo treatment, line of embryo and

Table 3. Tests of main effects for the experimental variants performed for parameter $\alpha$ of the logistic curves from the treatment effects model

\begin{tabular}{llc}
\hline \multicolumn{1}{c}{ Factor } & Main effects & $\begin{array}{c}\text { Estimated parametric } \\
\text { difference in } \alpha \\
\text { coefficients [mm] }\end{array}$ \\
\hline $\begin{array}{l}\text { No inhibition/ } \\
\text { Inhibition }\end{array}$ & Control - L27 & $10.24^{* *}$ \\
& Control - L122 & $7.24^{* *}$ \\
& Control - E1 & $8.03^{* *}$ \\
& Control - E3 & $9.45^{* *}$ \\
\hline Number of embryos & E1 - E3 & $1.43^{*}$ \\
\hline Line of embryo & L122 - L27 & $3.01^{* *}$ \\
\hline
\end{tabular}

Notation: parametric difference significant at " $\alpha=0.01^{*} \alpha=0.05$

Table 4. Tests of simple effects for the experimental variants holding the other factor fixed, for parameter $\alpha$ of the logistic curves from the treatment effects model

\begin{tabular}{lc}
\hline \multicolumn{1}{c}{ Simple effects } & $\begin{array}{c}\text { Estimated parametric difference } \\
\text { in } \alpha \text { coefficients }[\mathrm{mm}]\end{array}$ \\
\hline Control - L122E1 & $6.06^{* *}$ \\
Control - L122E3 & $8.41^{* *}$ \\
Control - L27E1 & $9.99^{* *}$ \\
Control - L27E3 & $10.49^{* *}$ \\
L122E1 - L122E3 & $2.35^{*}$ \\
L122E1 - L27E1 & $3.93^{* *}$ \\
L122E1 - L27E3 & $4.43^{* *}$ \\
L122E3 - L27E1 & $1.58^{\text {ns }}$ \\
L122E3 - L27E3 & $2.08^{*}$ \\
L27E1 - L27E3 & $0.50^{\text {ns }}$ \\
\hline
\end{tabular}

Notation: difference significant at " $\alpha=0.01, " \alpha=0.05^{\text {ns }}$ not significant

Table 5. Estimated random effects associated with Petri dish and random error from the treatment effects model

\begin{tabular}{lcccc}
\hline $\begin{array}{c}\text { Source } \\
\text { of variation }\end{array}$ & $\begin{array}{c}\text { Random } \\
\text { effect } \\
\text { parameter }\end{array}$ & Estimate & $2.5 \%$ & $97.5 \%$ \\
\hline Petri dish & $\sigma_{\mathrm{P}}$ & 1.10 & 0.71 & 1.68 \\
Random error & $\sigma_{\mathrm{E}}$ & 0.81 & 0.71 & 0.93 \\
\hline
\end{tabular}

number of embryos, on $\beta_{0}$ and $\beta_{1}$ coefficients of the logistic curve, however, were not confirmed.

Experimental treatment with DS from three somatic embryos produced a small differential inhibitory response in mycelial growth relative to treatment with DS from only single embryo depending on the embryo line. The mycelium inhibitory reaction to presence of DS from somatic embryos L122 is by 4.43 $\mathrm{mm}$ larger due to presence of DS from one somatic embryo relative to three embryos of L27 ( $<0.01$ ). Statistical tests of the simple effects are presented in Table 4. Estimated random effects associated with Petri dish and random errors are shown in Table 5. Inclusion of random variation associated with Petri dish in the model was justified due to significant impact of stochastic effects of the Petri dish on the observed results of the experiment $(\mathrm{p}<0.01)$. It can be hypothesized that variation among fungal inocula used in this in-vitro experiment played a significant role together with other sources of variation.

\section{Discussion}

The inhibition of mycelial growth of fungus $P$. schweinitzii on diffused substances (DS) in agar MS medium from pre-cultured somatic embryos L27 was stronger compared to somatic embryos of line L122. It is evident, that embryos L27 show more intense passive defense and / or non-induced natural defense.

Numerous results from past dual culture experiments confirmed the idea, that tester $P$. schweinitzii shows inhibition of mycelial growth on substances causing growth correlative inhibitions of tissues and organs in plant. Outline of theory describing constitutive defense system in plants on the basis of integrity was presented by Hřib (1985). Among these substances determining growth correlative inhibitions and their network in plant organism, it is primarily auxin (IAA) at higher concentrations (Hřib 1985; Hřib et al. 1999) similar to cytokinin (Hřib et al. 1993), which may influence the formation of phenolic compounds (Schnablová et al. 2006). The mechanism of growth correlative inhibitions is formed also by growth inhibitors, such as ethylene, abscisic acid and others.

It must be emphasized that observed phenolic compounds play a significant role in the defense reactions of many plants against pathogenic fungi, mainly in induced defense. This is well-documented evidence concerning quantitative changes in these compounds caused by a pathogen (Farkas and Kiraly 1962, Cruickshank and Perrin 1964), as well as changes in oxidative-reductive activity of the tissue. Increase of the oxidative activity leads to accumulation of quinones and quinone-like derivatives, which have higher fungi toxic activity. 
Peroxidase and polyphenol oxidase are directly involved in the defense reactions of resistant plants against fungi (Rubin and Artsikhovskaya 1964, Lehrer 1969) and others. Also, in our experiments, increased activity of peroxidase, a manifestation of browning after 27 days in embryogenic line L27 was observed, compared to line L122. Second part of the study confirmed higher passive defense of somatic embryos of line L27 compared to line L122 tested with $P$. schweinitzii due to substances produced by the embryos and diffused in the medium.

The peroxidase and polyphenol oxidase activities and their relationship to browning in such cultures were compared with pine embryogenic and non-embryogenic cultures (Laukkanen et al. 1999). Visible browning was a typical feature of callus cultures derived from shoots tips of mature Scots pine (Pinus sylvestris L.). Accumulation of phenolic substances was shown by histochemical staining. In the experiment, peroxidase activity increased rapidly soon after the start of the culture period, and especially between the second and third weeks of culture. They conclude that browning is associated with cell changes. Callus cultures from shoot tips were characterized by rapid browning and inability to regenerate (Laukkanen et al. 2000).

An interesting experiment was carried out by Dowd and Norton (1995). Callus of the fungus and insects resistant corn inbred, Mp313E of differing ages and degrees of brownness was tested for effect on neonate larvae of the corn earworm, Helicoverpa zea. Older, browner, 8 weeks old callus caused significantly higher mortality of $H$. zea after two days compared to larvae fed 5 weeks old callus (brown or not) or pinto bean diet. Larvae fed on the 5 weeks old calli were significantly smaller after nine days compared to those fed on nonbrown callus of the same age. Corn allelochemicals associated with cell walls, were oxidized, i.e. produced a brown product, up to 10-fold more rapidly by peroxidase preparations of the brown callus compared to nonbrown callus. This information suggests the peroxidases are contributing to the browning through oxidation of phenolic acids and thereby enhancing resistance to insects.

Generally, enzymatic browning occurs mainly due to the oxidation of natural phenolic compounds to quinones, which in turn are polymerized to brown or dark pigments (Valentines et al. 2005). These pigments are mostly melanin-based. Melanin is commonly thought of as the agent that protects numerous life forms (Pugh et al. 2005), although melanin has been identified previously within plants (Kamei et al. 1997). The structural characterization of melanin polymers has been notoriously difficult due to their general insolubility of most solvents and because the subunits are linked by non-hydrolysable bonds.
It has been suggested that there is an association between peroxidase and the metabolism of aromatic compounds, plant hormones and lignification (Butt 1980). Kansagra et al. (2008) concluded that anionic peroxidase plays an important role in browning of the tissue.

In vivo, auxin oxidase is a complex consisting of peroxidase and number of effectors which regulate its activity. These effects involve mineral substances, phenols, cumarins, IAA protectors and organic acids. Auxin protectors occur especially in juvenile tissues. These phenolic compounds are also produced in wounded tissues (Šebánek et al. 1991).

Production of indole-3-acetic acid (IAA) and melanin by root-nodule bacteria Rhizobium-like strains described by Pongsilp and Nuntagij (2009). It is interesting that authors observed melanin production and $21.92 \pm 1.67 \mu \mathrm{g}$ IAA equivalent per ml culture in strain DASA 57003 (positive strain) and only $12.88 \pm$ $2.45 \mu \mathrm{g}$ IAA equivalent per $\mathrm{ml}$ culture in DASA 57053 (negative strain) where no melanin production was observed.

In future, it is our intention to perform testing of passive defense in regenerants from lines L27 and L122 by the method of dual cultures with pre-cultivation of emblings and subsequent removal with tester P. schweinitzii.

\section{Acknowledgements}

This study was financially supported by the VEGA Grant Agency, Project No. 2/014411. The authors are thankful to reviewers of this paper for numerous valuable comments and suggestions.

\section{References}

Bergmeyer H.U. 1974. Methods of enzymatic analysis 1. 2nd edition. Academic Press, New York, p. 495.

Berryman A.A. 1988. Towards a unified theory of plant defense. In: Mattson W.J., Levieux J., Bernard-Dagan C. (eds.) Mechanisms of woody plant defenses against insects. Search for pattern. Springer-Verlag, New York, Berlin, Heidelberg, London, Paris, Tokyo, pp. 39-55.

Butt V.S. 1980. Direct oxidases and related enzymes. In: Stumpf P.K., Conn E.E. (eds.) The Biochemistry of Plants, Vol. 2, Academic Press, New York, pp. 81-123.

Cowling E.B., Horsfall J.G. 1980. Prologue: How plants defend themselves. In: Horsfall J.G., Cowling E.B. (eds.) Plant disease: an advanced treatise. Vol. 5, Academic Press, New York, pp. 1-16.

Cruickshank I.A.M., Perrin D.R. 1964. Pathological function of phenolic compounds in plants. In: Harborne J. (ed.) Biochemistry of phenolic com- 
pounds. Academic Press, New York, pp. 511-544.

Dowd P.F., Norton R.A. 1995. Browning - associated mechanisms of resistance to insects in corn callus tissue. Journal of Chemical Ecology 21: 583-600.

Farkas G.L., Király Z. 1962. Role of phenolic compounds in the physiology of plant diseases and disease resistance. Phytopathologische Zeitschrift 44: 105-150.

Hřib J. 1985. An outline of the theory of plant defense system on the basis of plant integrity. Acta Universitatis Agriculturae, Fac. agronomica (series A), Brno, 33: 301-304.

Hřib J., Vooková B., Flak P. 1993. Effect of auxin, cytokinin, and glutamine on mycelial growth of Phaeolus schweinitzii. European Journal of Forest Pathology 23: 269-275.

Hřib J., Vooková B., Salajová T., Bolvanský M., Fl’ak P. 1995. Testing of embryogenic and non-embryogenic calli of European black pine (Pinus nigra Arn.) for defense reactions to the fungus Phaeolus schweinitzii. Biologia (Bratislava) 50: 403-410.

Hřib J., Vooková B., Janisch R. 1996. Defense reaction of pine megagametophyte in dual cultures with a basidiomycete. Biologia (Bratislava) 51: 429-433.

Hřib J., Vooková B., Flak P. 1999. In vitro growth response of wood-rotting fungi to IAA. Archiv für Phytopathologie und Pflanzenschutz 32: 503-520.

Kamei H., Koide T., Kojima T., Hasegawa M., Umeda T. 1997. Suppression of growth of cultured malignant cells by allomelanins, plant-produced melanins. Cancer Biotherapy and Radiopharmaceuticals 12: 47-49.

Kansagra M., Pawar V., Bhatt K., Chudasama R., Thaker V. 2008. Role of cationic and anionic peroxidase in browning of multiple shoots of carnation (Dianthus caryoiplyllus L.) in vitro. Indian Journal of Plant Physiology 13: 317-319.

Koch A. L. 1975. The kinetics of mycelial growth. Journal of General Microbiology 89: 209-216.

Laukkanen H., Häggman H., Kontunen-Soppela S., Hohtola A. 1999. Tissue browning of in vitro cultures of Scots pine: Role of peroxidase and polyphenol oxidase. Physiologia Plantarum 106: 337-343.

Laukkanen H., Rautiainen L., Taulavuori E., Hohtola A. 2000. Changes in cellular structures and enzymatic activities during browning of Scots pine callus derived from mature buds. Tree Physiology 20: 467-475.

Lehrer R.I. 1969. Antifungal effects of peroxidase systems. Journal of Bacteriology 99: 361-365.

Murashige T., Skoog F. 1962. A revised medium for rapid growth and bioassays with tobacco tissue cultures. Physiologia Plantarum 15: 473-497.
Pinheiro J.C., Bates D.M.Mixed-Effects Models in S and S-PLUS, 2000, Springer Verlag, pp. 512-521.

Pongsilp N., Nuntagij A. 2009. Genetic diversity and metabolites production of root-nodule bacteria isolated from medicinal legumes Indigofera tinctoria, Pueraria mirifica and Derris elliptica Benth. grown in different geographic origins across Thailand. American - Eurasian Journal of Agricultural and Environmental Sciences 6: 26-34.

Pugh N.D., Balachandran P., Lata H., Dayan F.E., Joshi V., Bedir E., Takino T., Moraes R., Khan I., Pasco D.S. 2005. Melanin: dietary mucosal immune modulator from Echinacea and other botanical supplements. International Immunopharmacology 5: 637-647.

Nahálková J., Asiegbu F.O., Daniel G., Hřib J., Vooková B., Pribulová B., Gemeiner P. 2001. Isolation and immunolocalization of a Pinus nigra lectin (PNL) during interaction with the necrotrophs - Heterobasidion annosum and Fusarium avenaceum. Physiological and Molecular Plant Pathology 59: 153-163.

Rubin B.A., Artsikhovskaya E.V. 1964. Biochemistry of pathological darkening of plant tissues. Annual Review of Phytopathology 2: 157-178.

Salaj T., Matúšová R., Salaj J. 2004. The effect of carbohydrates and polyethylene glycol on somatic embryo maturation in hybrid fir Abies alba $\times$ Abies numidica. Acta Biologica Cracoviensia, Series Botanica 46: 159-167.

Schenk R.U., Hildebrandt, A.C. 1972. Medium and techniques for induction and growth of monocotyledonous and dicotyledonous plant cell cultures. Canadian Journal of Botany 50: 199-204.

Schnablová R., Synková H., Vičánková A., Burketová L., Eder J., Cvikrová M. 2006. Transgenic ipt tobacco overproducing cytokinins overaccumulates phenolic compounds during in vitro growth. Plant Physiology and Biochemistry 44: 526-534.

Smith P.K., Krohn R.I., Hermanson G.T., Mallia A.K., Gartner F.H., Provenzano M.D., Fujimoto E.K., Goeke N.M., Olson B.J., Klenk D.C. 1985. Measurement of protein using bicinchoninic acid. Analytical Biochemistry 150: 76-85.

Šebánek J., Sladký Z., Procházka S. 1991. Experimental Morphogenesis and Integration of Plants. Academia Praha, pp. 31-32.

Terho M., Pappinen A., von Weissenberg K. 2000. Growth reactions of a Gremmeniella abietina isolate and Scots pine embryogenic tissue cultures differ in a host-parasite in vitro system. Forest Pathology 30: 285-295.

Valentines M.C., Vilaplana R., Usall J., Larrigaudière C. 2005. Involvement of enzymatic browning and peroxidase activity as resistance mechanisms in "Golden Delicious" apples. Acta Horticulturae 682: 2041-2047. 
Vooková B., Kormu ák A. 2002. Some features of somatic embryo maturation of Algerian fir. In Vitro Cellular and Developmental Biology-Plant 38: 549-551.
Vooková B., Hřib J., Kormu ák A., Adamec V. 2006. Defence reactions of developing somatic embryos of Algerian fir (Abies numidica). Forest Pathology 36: 215-224. 